\title{
EVALUATION OF ADJUNCTIVE EFFECT OF DAILY DIETARY SUPPLEMENTS WITH OMEGA 3 AND PROPOLIS TO NON-SURGICAL PERIODONTAL THERAPY: RANDOMIZED CLINICAL TRIAL
}

\author{
Hany Kamel Shalaby* and Shaimaa Mohammed Morsy**
}

\begin{abstract}
Background and Objective: This study aimed to investigate the systemic effect of dietary supplement omega $3(\omega-3)$ polyunsaturated fatty acids (PUFAs) and propolis as an adjunct to non surgical periodontal therapy and evaluate the gingival crevicular fluid level of receptor activator of nuclear factor $x$ ligand (RANKL).
\end{abstract}

Material and Methods: Forty-five subjects with stage II or III and grade B periodontitis were included in this study. They were randomly assigned into three groups: Group I: 15 subjects received scaling and root planing (SRP) only. Group II: 15 subjects received SRP combined with daily dietary supplementation of omega 3 for 6 months. Group III: 15 subjects received SRP combined with a daily dietary supplement of propolis for 6 months. Clinical parameter (plaque index, bleeding index, pocket depth, and clinical attachment level) and biochemical analysis of RANKL in GCF were recorded at baseline, 3 months and 6 months after treatments

Results: Statistical analysis revealed that both $(\omega-3)$ and propolis statistically significant $(\mathrm{P} \leq 0.01)$ reduce $\mathrm{PD}$ and $\mathrm{CAL}$ at 3 and 6 months compared to its baseline and control group. RANKL level in GCF statistically significant $(\mathrm{P} \leq 0.01)$ reduced at 3 and 6 months in both treated groups compared to its baseline and control group. No statistical significant $(\mathrm{P} \geq 0.05)$ difference between both treated groups concerning clinical and biochemical parameters.

Conclusion: The present study suggests that dietary supplementation with $\omega-3$ PUFAs or propolis effective as an adjunct to nonsurgical periodontal therapy in the management of patients with periodontitis.

Keywords: Periodontitis; Dietary supplements ( $\omega-3)$; propolis; RANKL

\section{INTRODUCTION}

Periodontitis is one of the most prevalent inflammatory diseases, where the periodontal pocket formation, clinical attachment loss, and alveolar bone destruction are the most characteristic feature of the disease. ${ }^{1}$

The role of host-microbial interactions as well as the impact of environmental and genetic factors

\footnotetext{
* Assistant Professor Of Oral Medicine And Periodontology Faculty Dentistry Suez Canal University

** Lecturer of Oral Medicine And Periodontology Faculty Dentistry Suez Canal University
} 
in periodontitis is well recognized and demonstrates its multifactorial nature. ${ }^{2}$ Although bacteria are thought to be a primary inducer of periodontitis, also dysregulation of the host immune-inflammatory response are now held responsible for most clinical features and periodontal tissue destruction. ${ }^{2,3}$

As a consequence, a new concept for the treatment of periodontal diseases with host modulatory therapy (HMT) has emerged. The main objective of HMT is to modify or downregulate the destructive aspects of the host response and by upregulating the protective or regenerative responses to reduce tissue destruction and stabilize or even regenerate the periodontium. ${ }^{4}$ HMT is used as an adjunct to conventional periodontal treatment and delivered systemically or locally as part of a patient's periodontal therapy. ${ }^{5}$

Fish oil is a prime source of omega- 3 polyunsaturated fatty acids ( $\omega$-3 PUFAs) where the components are eicosapentaenoic acid (EPA) and docosahexaenoic acid (DHA). EPA and DHA compete with arachidonic acid (AA) for the cyclooxygenase (COX) and lipoxygenase (LOX) pathways, which result in the decrease production of highly active AA metabolites. ${ }^{6}$ It decrease the production of prostaglandin E2 (PGE2) metabolites, ${ }^{7}$ and decrease leukotriene B4 formation, which considered to be is an inducer of inflammation and a powerful inducer of leukocyte chemotaxis and adherence. ${ }^{8}$ For this purpose, Fish oil has gained attention as an HMT due to its ability to reduce inflammation. ${ }^{9} \omega-3$ PUFAs has been suggested in the treatment of several chronic diseases with low-grade systemic inflammation involving inflammatory bowel disease, cardiovascular diseases, rheumatoid arthritis, cancer, and periodontitis $\mathbf{1 0 , 1 1}$. The anti-inflammatory hallmarks, together with the good tolerance of omega-3 fatty acids by many individuals, has explained their use in periodontal disease treatment. ${ }^{12}$

Bee glue or propolis is an attractive natural product because of its unique biological functions. It is a natural resinous product that honeybees gather from different plants and mix with varying amounts of beeswax and salivary enzymes. The safety of propolis is emphasized not only by its usage as a folk medicine for a long history but by in vitro and in vivo safety assessment studies. ${ }^{13,14}$ Various properties of propolis have been studied and reported extensively including its antiinflammatory, antifungal, antibacterial, antiviral, immunomodulatory, antitumor properties. 15,16,17 This anti-inflammatory activity can be attributed to the presence of active flavonoids and cinnamic acid derivatives. The former includes acacetin, quercetin, and naringenin while the latter include caffeic acid phenyl ester (CAPE) and caffeic acid (CA). ${ }^{18}$ propolis has been used to treat periodontal disease due to its numerous and various effects on oral health. ${ }^{19}$

RANK-L is a transmembrane molecule of the tumor necrosis factor (TNF) ligand superfamily. In the presence of the permissive factor macrophage colony-stimulating factor (M-CSF), RANK-L is the fundamental and eventual common signal required both in vitro and in vivo for full osteoclast differentiation from multipotential hematopoietic precursor cells into mature multinucleated boneresorptive osteoclasts. ${ }^{20,21}$ Study on GCF of adult patients with chronic periodontitis showed that level of cytokine RANK-L in the GCF is a significantly higher in chronic periodontitis than in healthy subjects which might reflect the correlation between this osteoclastogenic protein and alveolar bone and teeth loss, and provide reliable information on the state of periodontal disease activity. ${ }^{22}$

The present study was investigated to compare the impact of daily oral dietary supplementation of $\omega-3$ PUFA and propolis capsule as an adjunct of standard periodontal therapy (scaling and root planing SRP). Also, we aimed to estimate levels of RANKL as a promising biomarker for bone turn over to evaluate the effect of those dietary supplements on its expression. 


\section{MATERIAL AND METHODS}

\section{Study Population}

This randomized clinical study was conducted on Forty-five subjects, with age range 35-55 years of age. The subjects were enrolled in the study from the Periodontology clinic at the Faculty of Dentistry, Suez Canal University, between April and December 2018. The objectives and the nature of the study including benefits and risks were clarified to the subjects and then written consent was full signed before entry into the study.

\section{Inclusion and exclusion criteria}

Subjects suffering from stage II or III periodontitis with grade $\mathrm{B}$ were included in this study, according to 2017 world workshop classification of periodontal disease. Subjects with interdental clinical attachment loss (CAL) $\leq 5$ $\mathrm{mm}$ of more than $30 \%$ of teeth and radiographic evidence of bone loss extending to coronal third (stage II) or extending to the mid-third of root and beyond with CAL $\geq 5 \mathrm{~mm}$ in stage III The participants were excluded from the study if they were pregnant or lactating women, suffering from systemic disease or were taking any medication that could affect their periodontal conditions. They had neither taken antibiotics within the last six months nor nonsteroidal anti-inflammatory drugs within the last three months. Also, subjects taking $\omega$ 3-PUFA or propolis as a nutritional supplement were excluded from the study.

\section{Study design}

At the baseline visit, complete dental examination for all subjects was received for initial documentation, including medical history, dental history, complete periodontal charting, panoramic radiographs, and a comprehensive treatment plan. Single full-mouth SRP was performed for all patients as initial therapy by manual and ultrasonic instrumentation as necessary, and oral hygiene instructions were given.

During the enrolment visit, a code number was given for each patients, and computer-generated table were used with 45 numbers randomly distributed into three blocks to allocate them to one of the three therapeutic groups (15 patients each)

Group 1 was assigned to receive SRP alone (control), whereas group 2 in SRP combined with orally administered dietary supplementation with w 3 PUFAs (Omega 3 plus* for 6 months. Group 3 SRP combined with orally administered PRO $400^{* *}$ once daily for 6 months. The subjects began taking the medication on the first day of the procedure.

The medication usage was informed to the subjects by written and verbal instructions. To ensure the patient's compliance the pills were placed in a bottle, and every 4 weeks during the study, the patients came to the clinic to refill their bottles with medication. Every month the desired amount of medication was given with extra number pills supplied in each bottle and residual pills were gathered and counted. Examination of oral soft and hard tissue was performed and side effects were recorded.

Clinical measurements, gingival crevicular fluid sampling, as well as reinforcement of oral hygiene at baseline and during follow-up evaluation were carried out at baseline, 3 months and 6 months.

\section{Clinical parameters}

Pocket depth (PD), clinical attachment level (CAL), plaque index (PI) ${ }^{23}$, bleeding index (BI) ${ }^{24}$ were recorded for each patient at baseline, 3 months and 6 months post-treatment. PD and CAL were recorded with calibrated William`s probe at 6 sites per tooth, the recorded readings were used to generate mean values at each time point.

\footnotetext{
* SEDICO Pharmaceutical Co., 6 October City, Egypt; 1 g, three times daily, $3 \mathrm{~g}$ fish oil)

** (BioPropolis capsule; Sigma Pharmaceutical Industries, Egypt)
} 


\section{Gingival crevicular fluid sampling}

For a minimum of 2 hours before the collection of GCF sampling, the participants were refrained from eating. Tooth with deepest pocket depth and more severe CAL in each quadrant were selected for GCF sampling. The GCF sample was taken from the buccal aspect of the selected tooth. Tooth associated with increased bleeding index were avoided as a test site to avoid salivary contamination, cotton roll and saliva ejector were used to isolate the selected tooth. Using sterile periodontal curette, the supragingival plaque was lightly removed after gentle air drying of the selected tooth. ${ }^{25}$ a strip* was then gently placed within pockets until mild resistance was felt and left in place for $30 \mathrm{~s}$.

Mechanical trauma was avoided and the strips contaminated with blood were discarded. The strips were placed in an Eppendorf tube containing $175 \mu 1$ phosphate-buffered saline (PBS) $\mathrm{pH} 7.2$. The samples were left at $4^{\circ} \mathrm{C}$ for $3 \mathrm{~h}$ after shaking gently for $1 \mathrm{~min}$. Then the tubes were centrifuged at $800 \mathrm{~g}$ for $5 \mathrm{~min}$. Finally, the supernatants were collected and stored at $-80 \mathrm{C}$ for subsequent assays. ${ }^{26}$

\section{RANKL assay}

RANKL was assayed by using an enzymelinked immunosorbent assay kits** This assay is a sandwich enzyme-linkedimmunosorbent assay and was accomplished according to the manufacturer's instructions using human recombinant standards. The RANKL concentration was then expressed in picograms per milliliter. ${ }^{26}$

\section{Statistical analysis}

Data were collected, compared then statistically analyzed. Numerical data were explored for normality by checking the distribution of data and using tests of normality (Kolmogorov-
Smirnov and Shapiro-Wilk tests). All data showed normal (parametric) distribution. All values were presented as means \pm standard deviations. First, we performed the Levene's tests for homogeneity of variance, which is a standard assumption of oneway analysis of variance (ANOVA) ${ }^{27}$ The results of the tests indicated the $\mathrm{P}$ values are greater than 0.01 , demonstrating that the variance within each of the populations is equal (i.e., the homogeneity of variance is violated). Then, one-way ANOVA with Bonferroni post hoc tests was performed for the evaluation of statistical significance among the groups. $\mathrm{P}<0.01$ was considered to be statistically significant.

Statistical analysis will be performed using the computer program SPSS software for windows version $22.0^{* * * *}$ at significant levels 0.01 (P-Value $\left.\leq 0.1\right)$.

\section{RESULTS}

Forty-five patients with an age ranged between 35-55 years old. No statistically significant difference between groups at baseline. The use of medication as an adjunct to conventional nonsurgical therapy showed no major deviation. Scheduled maintenance visits were performed for all patients who were participated in the study. The final analysis involve no dropped out patient, where the subjects that lost during the follow up were replaced.

Table 1 summarizes the clinical parameters of all groups at different time intervals. No significant differences between groups concerning PI $(\mathrm{P}>0.05)$ as plaque accumulation was kept at a minimum throughout the study. For all groups, PI reduction was maintained for 6 months. All groups result in improvement in bleeding index at 3 and 6 months with a statistically significant difference $(\mathrm{P} \leq 0.01)$ compared to baseline and no statistically significant

\footnotetext{
* (periopaper®, Amityville, NY, USA)

** (Bender Med Systems, Vienna, Austria)

*** (Statistical Package for Social Science, Armonk, NY: IBM Corp)
} 
difference $(\mathrm{P}>0.05)$ between groups at different time intervals.

PD was not statistically significantly different $(\mathrm{P}>0.05)$ between groups at baseline. At 3 and 6 months, all treatment modality results in a significant reduction of $\mathrm{PD}(\mathrm{P} \leq 0.01)$ compared to baseline with no statistically significant difference $(\mathrm{P}>0.05)$ between 3 and 6 months. As showed in Table 2, a Comparison of PD between groups showed a statistically significant difference $(\mathrm{P} \leq 0.01)$ for group II and group III compared to the control group at 3 and 6 months and no statistically significant difference $(\mathrm{P}>0.05)$ between group II and group III. Same as PD, CAL was not statistically significant (P $>0.05)$ at baseline between the three groups where mean CAL was $4.28 \pm 0.57$ in the control group and $4.08 \pm 0.96$ and $4.20 \pm 0.93$ for group II and III respectively. At 3 and 6 months, CAL in the control group reduced to $3.69 \pm 0.80$ and $3.49 \pm 0.85$ which were statistically significant $(\mathrm{P} \leq 0.01)$ compared to baseline with no statistically significant difference (P >0.05) between 3 and 6 months. In omega 3 treated group CAL was $2.86 \pm 0.58$ and $2.60 \pm 0.52$ at 3 and 6 months respectively that showed statistically significant difference compared to CAL in baseline.
While when compare CAL $2.98 \pm 0.68$ and 2.86 \pm 0.68 in propolis treated group at 3 and 6 months respectively to omega 3 treated group there were statistical significant difference $(\mathrm{P}>0.05)$. Also, $\mathrm{CAL}$ at 3 and 6 months in the propolis treated group showed no statistically significant difference ( $\mathrm{P}>0.05)$ compared to each other but statistically significant $(\mathrm{P} \leq 0.01)$ compare to $\mathrm{CAL}$ in the control group at 3 and 6 months.

RANKL level within GCF (picograms per milliliter) of all three groups are summarized in Table

3 \& figure 1 . No statistically significant difference ( $\mathrm{P}>0.05)$ between the three groups at baseline. At 3 and 6 months, the RANKL level within GCF showed statistically significant $(\mathrm{P} \leq 0.01)$ decrease at 3 and 6 months within the three groups compared to baseline with no statistically significant changes $(\mathrm{P}>0.05)$ between its level at 3 and 6 months. Comparison between groups showed statistically significant reduction $(\mathrm{P} \leq 0.01)$ of RANKL level in group II and III at 3 and 6 months compared to control group while no statistically significant difference $(\mathrm{P}>0.05)$ between group II and III at 3 and 6 months.

TABLE (I) Results repeated measures analysis of variance for the effect of treatment and time on PI \& BI.

\begin{tabular}{|c|c|c|c|c|c|c|c|c|}
\hline \multirow{2}{*}{ Groups } & \multicolumn{3}{|c|}{ Plaque index } & \multirow[b]{2}{*}{$\begin{array}{c}\text { P- value } \\
<0.01\end{array}$} & \multicolumn{3}{|c|}{ Bleeding index(BI) } & \multirow[b]{2}{*}{$\begin{array}{c}\text { P- value } \\
<0.01\end{array}$} \\
\hline & Base & 3 months & 6 months & & Base & 3 months & 6 months & \\
\hline SRP & $2.24^{\mathrm{a}} \pm 0.45$ & $0.74^{\mathrm{b}} \pm 0.51$ & $0.61^{\mathrm{b}} \pm 0.30$ & $0.000 * *$ & $2.03^{\mathrm{a}} \pm 0.49$ & $0.80^{\mathrm{b}} \pm 0.45$ & $0.57^{\mathrm{b}} \pm 0.30$ & $0.000 * *$ \\
\hline Omega 3 & $2.13^{\mathrm{a}} \pm 0.57$ & $0.62^{\mathrm{b}} \pm 0.29$ & $0.51^{\mathrm{b}} \pm 0.23$ & $0.000 * *$ & $1.95^{\mathrm{a}} \pm 0.53$ & $0.69^{b} \pm 0.24$ & $0.47^{\mathrm{b}} \pm 0.25$ & $0.000 * *$ \\
\hline propolis & $2.00^{\mathrm{a}} \pm 0.46$ & $0.65^{\mathrm{b}} \pm 0.32$ & $0.63^{b} \pm 0.25$ & $0.000 * *$ & $1.98^{\mathrm{a}} \pm 0.55$ & $0.70^{b} \pm 0.31$ & $0.53^{b} \pm 0.26$ & $0.000 * *$ \\
\hline $\mathrm{P}$ - value $<0.01$ & $0.438 \mathrm{~ns}$ & $0.684 \mathrm{~ns}$ & $0.474 \mathrm{~ns}$ & & $0.922 \mathrm{~ns}$ & $0.673 \mathrm{~ns}$ & $0.621 \mathrm{~ns}$ & \\
\hline
\end{tabular}


TABLE (2) Results repeated measures analysis of variance for the effect of treatment and time on PD \& CAL

\begin{tabular}{|c|c|c|c|c|c|c|c|c|}
\hline \multirow{2}{*}{ Groups } & \multicolumn{3}{|c|}{$\mathrm{PD}$} & \multirow{2}{*}{$\begin{array}{c}\text { P-value } \\
<0.01\end{array}$} & \multicolumn{3}{|c|}{ CAL } & \multirow{2}{*}{$\begin{array}{c}\text { P-value } \\
<0.01\end{array}$} \\
\hline & Base & 3 months & 6 months & & Base & 3 months & 6 months & \\
\hline SRP & $5.82^{\mathrm{a}} \pm 0.61$ & $4.64^{\mathrm{b} \S} \pm 0.73$ & $4.31^{\mathrm{b} \S} \pm 0.84$ & $0.000 * *$ & $4.28^{\mathrm{a}} \pm 0.57$ & $3.69^{\mathrm{b}} \pm 0.80$ & $3.49^{\mathrm{b} \S} \pm 0.85$ & $0.000 * *$ \\
\hline Omega 3 & $5.47^{\mathrm{a}} \pm 0.94$ & $3.50^{\mathrm{b} \S} \pm 0.79$ & $3.14^{\mathrm{b} \S} \pm 0.64$ & $0.000 * *$ & $4.08^{\mathrm{a}} \pm 0.96$ & $2.86^{\mathrm{b} \S} \pm 0.58$ & $2.60^{b \S} \pm 0.52$ & $0.000 * *$ \\
\hline Propolis & $5.67^{a} \pm 0.68$ & $3.53^{\mathrm{b} \S} \pm 0.66$ & $3.01^{\mathrm{b} \S} \pm 1.01$ & $0.000 * *$ & $4.20^{\mathrm{a}} \pm 0.93$ & $2.98^{\mathrm{b}} \pm 0.68$ & $2.86^{\mathrm{b} \S} \pm 0.68$ & $0.000 * *$ \\
\hline$P$ - value $<0.01$ & $0.478 \mathrm{~ns}$ & $0.000 * *$ & $0.000 * *$ & & $0.818 \mathrm{~ns}$ & $0.006 * *$ & $0.004 * *$ & \\
\hline
\end{tabular}

$n s$; **means non-significant and significant difference respectively between the period at the same group at $P$-value $<0.01$

$\S$ at the same column means significant difference compared to baseline at P-value $<0.01$

TABLE (3) Results of the effect of treatment protocol on levels of RANKL in GCF

\begin{tabular}{|c|c|c|c|c|}
\hline \multirow{2}{*}{ Groups } & \multicolumn{3}{|c|}{ RANKL } & \multirow[b]{2}{*}{ P- value $<0.01$} \\
\hline & Base & 3 months & 6 months & \\
\hline SRP & $198.57^{\mathrm{a}} \pm 18.19$ & $100.00^{\mathrm{b} \S} \pm 7.36$ & $90.79^{\mathrm{b}} \pm 14.31$ & $0.000 * *$ \\
\hline Omega 3 & $201.43^{\mathrm{a}} \pm 27.13$ & $87.57^{\mathrm{b} \S} \pm 7.96$ & $74.86^{\mathrm{b} \S} \pm 10.61$ & $0.000 * *$ \\
\hline Propolis & $199.50^{\mathrm{a}} \pm 23.25$ & $84.29^{\mathrm{b} \S} \pm 11.32$ & $72.71^{\mathrm{b}} \pm 12.10$ & $0.000 * *$ \\
\hline$P$ - value $<0.01$ & 0.946 ns & $0.000 * *$ & $0.000 * *$ & \\
\hline
\end{tabular}

$n s ; * *$ means non-significant and significant difference respectively between the period at the same group at $P$-value $<0.01$

$\S$ at the same column means significant difference compared to baseline at $P$-value $<0.01$

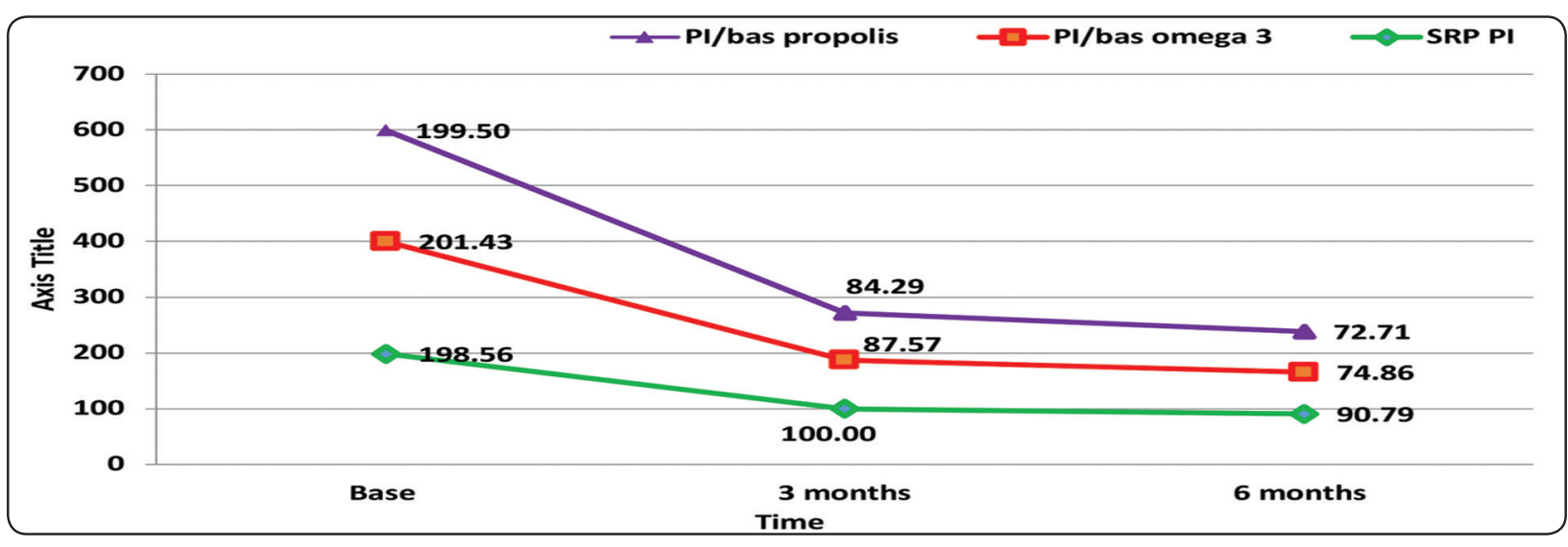

Fig. (1) The mean \pm standard deviation of RANKL levels in GCF significantly reduced at 3 and 6 months in all groups compared to the baseline level. But treated groups showed a statistically significant decrease in RANKL compared to SRP only. 


\section{DISCUSSION}

Nutritional factors have been suggested to have an impact on periodontal disease. That nutritional supplement (specifically with anti-inflammatory and antioxidant) enhances the periodontal disease status. The effectiveness of the nutritional intervention in the prevention and treatment of periodontal disease when used as an adjunct to non-surgical periodontal therapies has been evaluated. It has been shown that dietary supplements with antioxidants and antiinflammatory such as Biotene, green tea, omega-3, probiotics, and propolis could improve periodontal disease. ${ }^{28}$

The present study implies the successful use of dietary $\omega-3$ fatty acids and propolis as an adjunct to non-surgical treatment of periodontitis. In this clinical proof-of-concept study, daily administration of 3 grams of $\omega-3$ fatty acids in a fish-oil dietary supplement and $400 \mathrm{mg}$ propolis capsules for 6 months significantly improved the outcome of standard SRP using PD and CAL and standard indices as outcome measures. Besides, specific GCF markers of bone resorption (RANKL) were significantly reduced in the dietary supplement groups.

The effect of $\omega-3$ fatty acids as antiinflammatory is attributed to its ability to decrease the production of arachidonic acids metabolites PGE2 and leukotrienes B. $^{(7,8)}$ Moreover, DHA and or EPA precursor of omega-3 fatty acids could generate resolvins and protectins, endogenous antiinflammatory lipid mediators that act to resolve inflammation to diminish tissue damage and maximize tissue protection in acute inflammation. 29,30 EPA produces the E-series resolvins (e.g., RvE1, RvE2, and RvE3) while the D-series resolvins, protectins, and maresins are produced from its precursor DHA. ${ }^{31,32}$ studies on both acute and chronic models of inflammation showed that resolution of inflammation have been accelerated by endogenous resolvins. ${ }^{33,34}$ resolvins enhance and restore tissue integrity Through both antiinflammatory and pro-resolution mechanisms. ${ }^{32}$

In the present study, the significant improvement in BI, as well as in PD and CAL achieved at 3 and 6 months following $\omega-3$ PUFA as an adjunctive therapy, are in accordance with the study of Girish et al. who demonstrated the therapeutic efficacy of dietary supplementation of $\omega-3$ PUFA daily for 12 weeks as an adjunct to SRP. They concluded that there were significant reduction in the sulcus bleeding index, gingival index, PD, and CAL in the treated group compared to the controlled group at a 12-weeks period ${ }^{35}$.

However our study was not in accordance with Gisele et al., ${ }^{36}$ who failed to demonstrate any statistically significant difference in the clinical analysis of PD, CAL, VPI: visible, plaque index, bleeding on probing with daily dietary $\omega$-3 -PUFA for one year as an adjunct to SRP. The conflict between our results and this study may be due to small sample size included in their study where their study performed on only 15 subjects, 7 for test group and 8 for control group.

Also, Martinez et al., ${ }^{37}$ and Rosenstein et al. ${ }^{38}$, results showed that the $\omega$ - 3 dietary supplementation did not have an effect on the clinical outcome of the treatment. The difference in the results may be attributed to a shorter period of supplementation of the dietary supplements in their study where $\omega-3$ was administered for 4 months.

In the present study administration of propolis 400mg capsule daily for 6 months as an adjunct to nonsurgical periodontal therapy resulted in significant improvement of periodontal clinical parameters BI, PD, CAL compared to SRP alone at both 3 and 6 months. Our result may be attributed to the anti-inflammatory activity of CAPE which is a major component of propolis. ${ }^{39,40}$ The mode of anti-inflammatory activity of CAPE related to the suppression of arachidonic acid synthesis from the cell membrane; in return, the activity of the COX-1 
and COX-2 was inhibited as well as the activation of gene accountable for COX-2 expression was suppressed ${ }^{41,42}$

The results of the present research is in agreement with El-Sharkawy et al., ${ }^{43}$ who concluded that administration of $400 \mathrm{mg}$ propolis once daily for 6-month in type 2 diabetic patients with periodontitis is a potentially beneficial adjunct to SRP. Also they stated a significant improvement of PD, CAL, Eastman interdental bleeding index (EIBI), and gingival index (GI) outcome, with reduction of glycosylated hemoglobin (HbA1c) level, and Fasting plasma glucose (FPG).

Also in a study of Anees et al. ${ }^{44}$ they compared the effect of systemic administration of $400 \mathrm{mg}$ capsule propolis and moxifloxacin $400 \mathrm{mg}$ daily for 7 days as an adjunct to SRP. They concluded that both propolis and moxifloxacin significantly improve the PD, CAL, bleeding on probing and gingival index as well as significantly decrease the salivary level of IL-1 $\beta$ compared to SRP alone. Moreover, Nehal et al., ${ }^{45}$ reported that local subgingival delivery of propolis showed improvement in GI, PD, CAL compared to SRP alone in patients with chronic periodontitis.

RANKL bone marker which promotes the formation of bone-resorbing osteoclasts through its binding to osteoclast precursors is a common finding in periodontitis. ${ }^{46,47}$ In the current study systemic administration of omega 3 for 6 months as an adjunct to SRP significantly decreased RANKL level in GCF at 3 an 6 months compared to SRP alone with no statistically significant difference between its level at 3 and 6 months.

Several researches have documented that EPA and DHA can prevent NF- $x \mathrm{~B}$ activation. ${ }^{48,49}$ Because of its redox sensitivity, suppression of NF$x \mathrm{~B}$ activation may be through the reduced synthesis of reactive oxygen species. ${ }^{50}$ Also, a study of Berger et al., ${ }^{51}$ documented that omega 3 induces production of another transcription factor called peroxisome proliferator-activated receptor gamma (PPAR $\gamma)$ which has anti-inflammatory effects by directly regulating inflammatory gene expression, as well as interfering with the activation of $\mathrm{NF}-\varkappa \mathrm{B}^{51}$

The findings of the present study were in accordance with El-sharkawy et al. ${ }^{43}$ study that reported that systemic daily administration of omega 3 for 6 months combined with low dose aspirin as an adjunct to SRP significantly reduces the salivary concentration of RANKL compared to SRP alone.

Daily systemic administration of $400 \mathrm{mg}$ propolis in the current research resulted in a significant decrease in the GCF level of RANKL compared to SRP alone while no statistical significance between propolis and omega 3 at both 3 and 6 months.

The promising effect of propolis in reducing GCF level of RANKL in the present article may be explained by the stimulatory effect of CAPE on osteoclast apoptosis. ${ }^{52} \mathbf{H a}$ et al., ${ }^{53}$ demonstrated that caffeic acid phenyl ester (CAPE) can be used for the treatment of bone destructive diseases, due to its suppression effect on receptor activator nuclear factor-kB ligand. They explained their results through the effects of propolis active components that inhibit bone loss in cell cultures. CAPE through the inhibition of cell signaling pathways of RANKL induced NF-kB activity. With this evidence, researchers suggest that pathological bone diseases can be treated with $\mathrm{CAPE}^{54}$.

Our result was in agreement with a study of Toker et al., ${ }^{55}$ who examine the effect of systemic administration of propolis on morphometric and histopathologic changes associated with experimental periodontitis. They concluded that the systemic application of propolis in experimental periodontitis in rats can prevent further bone loss on the established histologic and morphologic picture.

Limitations of the present study include a small number of patients enrolled in this study. As well as systemic administration of medication daily for 
6 months did not suit several patients that refuse to enroll in this study.

The present study concluded that systemic administration of dietary supplement $\omega-3$ PUFA and propolis can be used effectively as an adjunct to nonsurgical periodontal therapy. More clinical studies on these dietary supplements to assess the microbiologic aspect in periodontitis and correlate it with clinical and biochemical findings are needed.

\section{REFERENCES}

1. Taylor JJ, Preshaw PM, Lalla E. A review of the evidence for pathogenic mechanisms that may link periodontitis and diabetes. J Clin Periodontol 2013;40(Suppl 14): S113S134.

2. Kornman KS. Mapping the pathogenesis of periodontitis: a new look. J Periodontol (2008), 79:1560-1568.

3. Preshaw PM, Taylor J. How has research into cytokine interactions and their role in driving immune responses impacted our understanding of periodontitis? J Clin Periodontol (2011), 38:60-84.

4. Meadows CL, Gher ME, Quintero G, Lafferty TA. A comparison of polylactic acid granules and decalcified freeze-dried bone allograft in human periodontal osseous defects. J Periodontol 1993;64:103-109.

5. Kubler N, Reuther J, Kirchner T, Priessenitz B, Sebald W. Osteoinductive, morphologic, and biomechanical properties of autolyzed, antigen-extracted, allogeneic human bone. J Oral Maxillofac Surg 1993;51:1346-1357.

6. Van der Merwe CF. A different and physiological approach to manipulating the inflammatory response. Eur J Gastroenterol Hepatol 1993;5:433-436.

7. Trebble, T. M., Wootton, S. A., Miles, E. A., Mullee, M., Arden, N. K., Ballinger, A. B., Stroud, M. A., Burdge, G. C. \& Calder, P. CProstaglandin E 2 production and T cell function after fish-oil supplementation: Response to antioxidant cosupplementation. American Journal of Clinical Nutrition. (2003b), 78, 376-382.

8. Serhan, C. N., Clish, C. B., Brannon, J., Colgan, S. P., Chiang, N. \& Gronert, K. Novel functional sets of lipid-derived mediators with antiinflammatory actions generated from omega-3 fatty acids via cyclooxygenase 2-nonsteroidal antiinflammatory drugs and transcellular processing. Journal of Experimental Medicine (2000), 192, 1197-1204.

9. Calder, P. C. Polyunsaturated fatty acids, inflammation, and immunity. Lipids (2001) 36, 1007-1024.

10. James, M., Proudman, S. \& Cleland, L. Fish oil and rheumatoid arthritis: past, present, and future. Proceedings of the Nutrition Society(2010), 69, 316-323.

11. Wall, R., Ross, R. P., Fitzgerald, G. F. \& Stanton, C. Fatty acids from fish: the anti-inflammatory potential of longchain omega-3 fatty acids. Nutrition Reviews (2010), 68, 280- 289 .

12. Iwasaki, M., Yoshihara, A., Moynihan, P., Watanabe, R., Taylor, G. W. \& Miyazaki, H. Longitudinal relationship between dietary omega-3 fatty acids and periodontal disease. Nutrition (2010), 26, 1105-1109.

13. Burdock GA. Review of the biological properties and toxicity of bee propolis (propolis). Food Chem Toxicol. 1998, 36(4):347-363.

14. Sforcin JM. Biological properties and therapeutic applications of propolis. Phytother Res. 2016. 30(6):894-905.

15. Araujo, M.A.R., Libério, S.A., Guerra, R.N.M., Ribeiro, M.N.S., Nascimento, F.R.F., Mechanisms of action underlying the anti-inflammatory and immunomodulatory effects of propolis: a brief review. Rev. Bras. Farmcogn, 2012.. 22, 208-219.

16. Machorowska-Pieniazek, A., Morawiec, T., Mertas, A., Tanasiewicz, M., Dziedzic, A., Król, W., Influence of propolis on hygiene, gingival condition, and oral microflora in patients with cleft lip and palate treated with fixed orthodontic appliances. Evid Based Complement Alternat Med. May 19, 2013

17. Vagish Kumar, L.S., Propolis in dentistry and oral cancer management. N. Am. J. Med. Sci. 2014. 6, 250-259.

18. ALMEIDA, E C D; MENEZES, H. Anti-inflammatory activity of propolis extracts: a review 2104. Journal of Venomous Animals and Toxins including Tropical Diseases. (2002) 8 (2): 191-212.

19. Koo H., Cury JA., Rosalen PL., Ambrosano GM., Ikegaki M., Park YK. Effect of a Mouthrinse Containing Selected Propolis on 3-day Dental Plaque Accumulation and Polysaccharide Formation. Caries Res. 2002;36(6):445-448.

20. Anderson DM, Maraskovsky E, Billingsley WL, et al. A homologue of the TNF receptor and its ligand enhance 
T-cell growth and dendritic-cell function. Nature 1997; 390:175-179.

21. Yasuda H, Shima N, Nakagawa N, et al. Osteoclast differentiation factor is a ligand for osteoprotegerin/ osteoclastogenesis inhibitory factor and is identical to TRANCE/ RANKL. Proc Natl Acad Sci (USA) 1998; 95:3597-3602.

22. Rolando Vernal, Alejandra Chaparro, Rebecca Graumann, Javier Puente, Maria Antonieta Valenzuela, and Jorge Gamonal $\uparrow$. Levels of Cytokine Receptor Activator of Nuclear Factor $\chi \mathrm{B}$ Ligand in Gingival Crevicular Fluid in Untreated Chronic Periodontitis Patients. J Periodontol 2004;75:1586-1591.

23. Turesky S, Gilmore ND, Glickman I. Reduced plaque formation by the chloromethyl analogue of victamine C. J Periodontol 1970;41: 1, 41-43.

24. Saxton CA, van der Quderra FJ. The effect of a dentifrice containing zinc citrate and triclosan on developing gingivitis. J Periodontal Res 1989;24:75-80.

25. Griffiths GS, Curtis MA, Wilton JM. Selection of a filter paper with optimum properties for the collection of gingival crevicular fluid. J Periodontal Res 1988;23:33-38.

26. Parichehr Behfarnia, Zahra Saied-Moallemi, Shaghayegh Haghjooy Javanmard, ${ }^{2}$ and Roohollah Naseri. Serum, saliva, and GCF concentration of RANKL and osteoprotegerin in smokers versus nonsmokers with chronic periodontitis. Adv Biomed Res. 2016; 5: 80.

27. R.J. Carroll, H. Schneider, A note on levene's tests for equality of variances, Stat. Probab. Lett. 3 (1985) 191-194.

28. - Djordjevic VB. Free radicals in cell biology. International Review of Cytology. 2004;237:57-89

29. Serhan, C. N., Hong, S., Gronert, K., Colgan, S. P., Devchand, P. R., Mirick, G. \& Moussignac, R. L. Resolvins: a family of bioactive products of omega-3 fatty acid transformation circuits initiated by aspirin treatment that counter proinflammation signals. Journal of Experimental Medicine (2002) 196, 1025-1037.

30. Hong, S., Gronert, K., Devchand, P. R., Moussignac, R. L. \& Serhan, C. N. Novel docosatrienes and 17S-resolvins generated from docosahexaenoic acid in murine brain, human blood, and glial cells. Autacoids in anti-inflammation. Journal of Biological Chemistry (2003) 278, 14677-14687.

31. Serhan, C. N., Brain, S. D., Buckley, C. D., Gilroy, D. W., Haslett, C., O’Neill, L. A., Perretti, M., Rossi, A. G. \&
Wallace, J. L. Resolution of inflammation: state of the art, definitions and terms. FASEB Journal (2007) 21, 325-332.

32. Isobe, Y., Arita, M., Matsueda, S., Iwamoto, R., Fujihara, T., Nakanishi, H., Taguchi, R., Masuda, K., Sasaki, K., Urabe, D., Inoue, M.\& Arai, H. Identification and structure determination of novel anti-inflammatory mediator resolvin E3, 17,18- dihydroxyeicosapentaenoic acid. Journal of Biological Chemistry (2012) 287, 10525-10534.

33. Arita, M., Yoshida, M., Hong, S., Tjonahen, E., Glickman, J. N., Petasis, N. A., Blumberg, R. S. \& Serhan, C. N. Resolvin E1, an endogenous lipid mediator derived from omega-3 eicosapentaenoic acid, protects against 2,4,6-trinitrobenzene sulfonic acid-induced colitis. Proceedings of the National Academy of Sciences of the United States of America (2005b) 102, 7671-7676.

34. Hasturk, H., Kantarci, A., Ohira, T., Arita, M., Ebrahimi, N., Chiang, N., Petasis, N. A., Levy, B. D., Serhan, C. N. \& Van Dyke, T. E. RvE1 protects from local inflammation and osteoclast-mediated bone destruction in periodontitis. FASEB Journal (2006) 20, 401-403.

35. Girish D. Deore, Abhijit N. Gurav, Rahul Patil, Abhijeet R. Shete, Ritam S. NaikTari, Saurabh P. Inamdar J. Omega 3 fatty acids as a host modulator in chronic periodontitis patients: a randomised, double-blind, palcebo-controlled, clinical trial. J Periodontal Implant Sci 2014;44:25-32

36. Gisele Lago Martinez, Josely Correa Koury, Marcela Anjos Martins, Fernanda Nogueira4, Ricardo Guimarães Fischer, Anders Gustafsson5, Carlos Marcelo S Figueredo. Serum level changes of long eISSN chain-polyunsaturated fatty acids in patients undergoing periodontal therapy combined with one year of Omega-3 supplementation: a pilot randomized clinical trial. J Periodontal Implant Sci 2014;44:169-177

37. Martinez GL, Koury JC, Brito F, Fischer RG, Gustafsson A, Figueredo CM. The impact of non-surgical periodontal treatment on serum levels of long chain-polyunsaturated fatty acids: a pilot randomized clinical trial. J Periodontal Res 2014;49:268-74.

38. Rosenstein ED, Kushner LJ, Kramer N, Kazandjian G. Pilot study of dietary fatty acid supplementation in the treatment of adult periodontitis. Prostaglandins Leukot Essent Fatty Acids 2003;68: 213-8.

39. S.-Y. Jo, N. Lee, S.-M. Hong, H. H. Jung, and S.-W. Chae. "Caffeic acid phenethyl ester inhibits diesel exhaust particle-induced inflammation of human middle ear 
epithelial cells via NOX4 inhibition," Annals of Otology, Rhinology, and Laryngology, 2013.vol. 122, pp. 595-600,

40. F. M. da Cunha, D. Duma, J. Assreuy et al., "Caffeic acid derivatives: in vitro and in vivo anti-inflammatory properties," Free Radical Research, 2004.vol. 38, no. 11, pp. 1241-1253

41. P. Michaluart, J. L. Masferrer, A. M. Carothers et al., "Inhibitory effects of caffeic acid phenethyl ester on the activity and expression of cyclooxygenase- 2 in human oral epithelial cells and in a rat model of inflammation," Cancer Research, 1999.vol. 59, no. 10, pp. 2347-2352,

42. K. W. Lee, K.-S. Chun, J.-S. Lee, K.-S. Kang, Y.-J. Surh, and H. J. Lee, "Inhibition of cyclooxygenase-2 expression and restoration of gap junction intercellular communication in H-rastransformed rat liver epithelial cells by caffeic acid phenethyl ester," Annals of the New York Academy of Sciences, vol. 1030,pp. 501-507, 2004.

43. El-Sharkawy H., Nayer Aboelsaad, Mohamed Eliwa, Mahmoud Darweesh, Mohammad Alshahat, Alpdogan Kantarci, Hatice Hasturk, and Thomas E. Van Dyke. Adjunctive Treatment of Chronic Periodontitis with Daily Dietary Supplementation With Omega-3 Fatty Acids and Low-Dose Aspirin. J Periodontol 2010;81:1635-1643

44. Anees M.M., Aboshady T. E., Elsharkawy H. M. Adminestration of systemic propolis versus Moxifloxacin as adjunctive treatment of severe generalised periodontitis. EGY.DENT. J 2019 65;147:157.

45. Nehal N Sanghani, Shivaprasad BM, savita S. Health from the Hive: Propolis as an Adjuvant in the Treatment of Chronic Periodontitis - A Clinicomicrobiologic Study Journal of Clinical and Diagnostic Research. 2014 Sep, Vol-8(9): ZC41-ZC44

46. Liu D, Xu JK, Figliomeni L, et al. Expression of RANKL and OPG mRNA in periodontal disease: Possible involvement in bone destruction. Int J Mol Med 2003;11:17-21

47. Faienza MF, Brunetti G, Colucci S, et al. Osteoclastogenesis in children with 21-hydroxylase deficiency on long- term glucocorticoid therapy: The role of receptor activator of nuclear factor-kappaB ligand/osteoprotegerin imbalance. J Clin Endocrinol Metab 2009;94:2269-2276.

48. Lo C-J, Chiu KC, Fu M, Lo R, Helton S Fish oil decreases macrophage tumor necrosis factor gene transcription by altering the NFxB activity. J Surg Res (1999) 82:216-221.

49. Novak TE, Babcock TA, Jho DH, Helton WS, Espat NJ NF- $x$ B inhibition by $\omega-3$ fatty acids modulates LPS-stimulated macrophage TNF- $\alpha$-transcription. Am J Physiol Lung Cell Mol Physiol (2003) 284:L84-L89.

50. Sanlioglu S, Williams CM, Samavati L, Butler NS, Wang G, McCray PB, Ritchie TC, Hunninghake GW, Zandi E, Engelhardt JF Lipopolysaccharide induces Rac1- dependent reactive oxygen species formation and coordinates tumor necrosis factor- $\alpha$ secretion through IKK regulation of NF-xB.J Biol Chem (2001) 276:30188-30198

51. Berger J, Moller DE The mechanisms of action of PPARs. Annu Rev Med (2002) 53:409-435

52. McEleny K, Coffey R, Morrissey C, et al. Caffeic acid phenethyl ester-induced $\mathrm{PC}-3$ cell apoptosis is caspasedependent and mediated through the loss of inhibitors of apoptosis proteins. BJU Int 2004;94(3):402-6.

53. Ha J, Choi HS, Lee Y, et al. Caffeic acid phenethyl ester inhibits osteoclastogenesis by suppressing NF kappaB and downregulating NFATc1 and c-Fos. Int Immunopharmacol 2009;9(6):774-80.

54. Ang E S, Pavlos NJ, Chai LY, et al.: Caffeic acid phenethyl ester, an active component of honeybee propolis attenuates osteoclastogenesis and bone resorption via the suppression of RANKL induced N) J Cell Physiol. 2009 Dec;221(3):642-9.

55. Toker H, Ozan F, Ozer H, Ozdemir H, Eren K, Yeler H. A morphometric and histopathologic evaluation of the effects of propolis on alveolar bone loss in experimental periodontitis in rats. J Periodontol 2008;79:1089-94. 